\title{
La relación entre ciencia y arte: Aportes para pensar una ciencia desde la dimensión artística nietzscheana
}

\section{The relationship between science and art: Contributions to think a science from the Nietzschean artistic dimension}

\author{
Yamila Rohaly \\ Estudiante del profesorado y la licenciatura en Filosofía \\ Universidad Nacional del Nordeste \\ yamilarohaly20@gmail.com
}

Resumen.

El presente artículo pretende mostrar cómo se concibe la relación entre el arte y la ciencia en la filosofía nietzscheana. A partir esta relación, se propone pensar y reflexionar sobre una forma de pensar a la ciencia, en la cual el arte y su movimiento creador se mostraría como originador de la misma.

Se puede percibir que el arte es recurrente en su pensamiento, transfigurando y modificando su manera de vincularlo a la vida, pero sin perder un plano prominente. Se realizará un recorrido intentando plasmar el camino que tuvieron sus consideraciones en torno a la temática, conforme avanza en su vida. Se intentará mostrar que enfrentando a su cultura, propone una manera experimental de vivir en la que el rol del filósofo-artista es clave.

Palabras claves: Arte - Vida - Ciencia - Voluntad de poder- Filosofo-artista

\section{Abstract.}

This article aims to show how the relationship between art and science is conceived in Nietzschean philosophy. From this relationship, it is proposed to think and reflect on a way of thinking about science, in which art and its creative movement would show itself as the originator of it.

It can be perceived that art is recurrent in his thought, transfiguring and modifying his way of linking it to life, but without losing a prominent plane. There will be a tour trying to capture the path that had its considerations around the theme, as it progresses in his life. An attempt will be made to show that confronting its culture, it 
proposes an experimental way of living in which the role of the philosopher-artist is key.

Keywords: Art - Life - Science - Will to power - Philosopher-artist

\section{Introducción}

El presente trabajo pretende dar a luz las teorizaciones sobre un aspecto de la estética nietzscheana: el arte; para luego, enfrentarlo (¿o aproximarlo?) con la ciencia, mostrando cómo se da la relación entre estos polos opuestos, si es que existe tan marcada contraposición. Es conveniente en este punto, revisar cuál es el plano que ocupa el arte actualmente en nuestra sociedad capitalista. Cuando comienza el auge de la sociedad capitalista, se tergiversa este aprecio por el arte sin más. Aquí la obra en sí misma ya no es lo importante, comienzan a tenerse en cuenta otras cuestiones que podrían denominarse banales, pero que van de la mano con un sistema que fomenta el competitivismo debajo del velo de la meritocracia. $Y$ con esto último se hace referencia a que en este contexto, lo que interesa es lo externo, impresionar al público o a las masas, y tener su adoración, para esto la obra artística en si misma queda velada por este afán y orgullo propio de un sistema que no permite su aprecio como tal.

Se intentará mostrar cómo, imponiéndose a su cultura, Friedrich Nietzsche (1844 - 1900) observa al arte como una actividad de crucial importancia en todos los aspectos de la vida humana, llegando a considerarlo como vital. Además, se pretende mostrar cómo su pensamiento da un giro si tomamos su juventud y su periodo de madurez. Si bien, existen continuidades muy notables, se notará cómo hay cambios de significaciones y de sentidos, que a la vez permiten entender la complejidad de su pensamiento.

La dimensión estética, en el pensamiento nietzscheano, sufrió alteraciones a medida que avanzó su vida, tales cambios están directamente relacionados que las circunstancias sobre las que transcurrió. Desde su infancia, fue notable su inclinación por lo artístico, por la poesía y la música principalmente, llegando a componer algunas sonatas de piano. Su amistad con Wagner, tan marcada en su pensamiento tal como la 
ruptura de ese vínculo, lo condujo a establecer una figura determinada del artista y romper así con algunas de sus postulaciones de juventud sobre el arte.

Nos parece prudente comenzar por caracterizar por qué llega el filósofo a considerar al de vital importancia para la vida, teniendo atención en qué aspectos o concepciones de su pensamiento podrían destacarse como sostén de esta postura; luego, entrar en el terreno del vínculo "arte-vida" mostrando como la vida se determina 0 , más bien, se transfigura a raíz del movimiento que produce y el constante cambio que acarrea el arte. Estas consideraciones pertenecen propiamente a los primeros escritos del filósofo, que mas tarde adquieren otro sentido. No se trata de un sentido contradictorio a este, sino más bien un sentido ampliatorio y mas acorde a lo que postula en esta época. Por lo tanto, deja el arte de tener un tinte metafísico y comienza a tener una expresión fisiológica, relacionado con la tierra y lo orgánico. Se pretende mostrar este giro o re-significación, haciendo hincapié en la filosofía experimental que nos propone.

Esta exposición sobre el arte pretende preparar el terreno para una posterior confrontación con la ciencia, en total contradicción con la dimensión artística, prestando especial atención a la forma en que se la debe empezar a concebir, tal como nos propone el filósofo y desarrollando el rol del filósofo-artista en esta nueva forma de ciencia o filosofía experimental. A raíz de esta confrontación, y teniendo en cuenta una de las concepciones fundamentales de su pensamiento, la concepción de Voluntad de Poder, buscaremos responder a ciertos interrogantes.

En este punto, servirá para producir una crisis con las concepciones de grandes pensadores filosóficos y a partir de tal crisis, se pretenderá reconstruir una forma diferente de concebir la ciencia o pensarla a la luz de todo lo desarrollado. Partiendo desde las características de cada dimensión ¿cómo se da la relación entre arte y ciencia? ¿bajo que términos se da la supremacía de una sobre la otra?

Si pensamos en la Voluntad de Poder, Voluntad de Vida, presente en todo ente existente y con la particularidad azarosa de moverse, ¿cómo es posible que este vínculo sea una dominación estática hace siglos? En esta lucha de instintos que supone la Voluntad de Poder, ¿̇se podría hablar de dominación o posesión estática? 
Ante todas estas cuestiones, ¿cómo es posible conciliar la Voluntad de Poder que tiene como regla un "lanzamiento de dados" - con la primacía de la ciencia sobre el arte? Si es posible esta conciliación, ¿como se torna evidente? ¿qué aspectos se podrían destacar para vislumbrarla? Para intentar responder a estas cuestiones se comenzará a desarrollar el trabajo en diferentes apartados, de manera que en cada uno se introduzca un aspecto de la temática.

\section{Caracterización del arte entendido desde la Voluntad de Poder.}

No es posible hablar de la dimensión artística de Nietzsche sin hacer referencia a nociones fundamentales de su pensamiento, que transversan notablemente esta temática. Si bien nuestro filósofo, intentó mostrar que su pensamiento no era estructurado ni sistemático, podemos penetrar en sus nociones y notar cómo cada una influencia a otra, y cómo todo su pensamiento se entiende desde la perspectiva de estas nociones. Una de ellas es la de Voluntad de Poder, la cual desarrollaremos mínimamente, sin ánimos de extendernos demasiado. Pero otorgándole un lugar menester dentro de este trabajo, a causa de su importancia en vinculación a esta temática, como en toda su obra.

La Voluntad de Poder, como varias concepciones dentro de este pensamiento, fueron cambiando de sentido. En el joven Nietzsche, esta noción estaba influenciada por rasgos de la filosofía de Schopenhauer, la cual es una filosofía pesimista por lo que también Nietszche tomaba a la voluntad con ciertos rasgos negativos. Esta voluntad, también le sirve para concebir al arte como una actividad metafísica. Más tarde, en su pensamiento adulto, cambia el sentido y moldea esta noción, la envuelve de aspectos que permiten afirmar y potenciar la vida, es decir, que los tintes pesimistas dejan de tener influencia aquí.

Esta noción, ya en su pensamiento emancipado, revela el movimiento continúo y azaroso mediante el cual devienen las cosas. Para Nietzsche, nada está predeterminado, como puede afirmar con convicción el Cristianismo, sino por el 
contrario, sucede por azar; es posibilitado por la Voluntad de Poder ${ }^{1}$, que tiene como regla un "lanzamiento de dados". Así de paradójico. Ilustrando esta cuestión, advierte que de manera inmanente a la voluntad, existe una lucha continúa de fuerzas en puja, que buscan imponerse una a la otra. El resultado de esta lucha, es decir, el instinto que predomina en ella, es el que posibilita una acción o acto humano. De esta misma manera, sucede con todo acto de la vida cotidiana. Además, esta noción demuestra una constante transfiguración, ya que este instinto que llegó a predominar, no permanece victorioso de una vez y para siempre, sino que repentinamente cuenta con otros instintos que buscan derrocarlo, en vistas de una nueva dominación y acción.

De esta manera, la voluntad de poder posibilita la dominación de un motivo sobre otro. Así, es utilizada para explicar diversos campos de su pensamiento. La vida, es uno de estos campos y constituye un concepto complejo de entender en la filosofía nietzscheana. La voluntad de Poder afirma la vida, pero lo interesante es que la afirma oponiéndose a todo lo que pueda conservarla. Es decir que no intenta prolongarla necesariamente, ya que se considera que de esa manera la misma vida es negada e interrumpida en su devenir.

"La voluntad de poder no lucha por vivir porque teme la muerte. La voluntad de poder lucha porque quiere la vida y quiere expresarse a través de ella. La voluntad es una energía que desea más vida. $\mathrm{Y}$, en todo caso, la muerte es parte del proceso vital. Por ello, no debe vérsela como una ladrona. La muerte es regalo para quien está en conexión con la tierra. Ella marca el cierre o el traspaso de un ciclo que debe dejar lugar a otro nuevo". ${ }^{2}$

\footnotetext{
1 Martín Heidegger, respecto de esta noción: "La expresión «voluntad de poder» nombra el carácter fundamental del ente; todo ente que es, en la medida en que es, es voluntad de poder. De este modo se dice qué carácter tiene el ente en cuanto ente. Pero con ello de ninguna manera se responde a la primera y auténtica pregunta de la filosofía, sino sólo a la última pregunta previa. Para aquel que en el final de la filosofía occidental aún puede y tiene la necesidad de preguntar de modo filosófico, la pregunta decisiva no es ya simplemente la que se plantea cuál es el carácter fundamental que muestra el ente, cómo se caracteriza el ser del ente, sino la pregunta: ¿qué es este ser mismo? Es la pregunta por el «sentido de ser», no sólo por el ser del ente; y el concepto de «sentido» está aquí exactamente delimitado como aquello desde donde y en base a lo cual el ser en cuanto tal puede revelarse y llegar a la verdad.[...]¿Qué y cómo es la voluntad de poder misma? Respuesta: el eterno retorno de lo mismo."(M. Heidegger, Nietzsche, Tomo I, pp 31)

2 ALDONATI, LUCAS GONZALO Artista como espíritu libre en La ciencia Jovial y Así habló Zaratustra de Friedrich Nietzsche. Tesis de Licenciatura. 2017 pp 27
} 
En este punto, es que propone una economía de fuerzas respecto de la vida y la salud. Se debe ser capaz de dominar la propia voluntad de poder para así alejar aquellos instintos que buscan destruirnos. Pero a la vez, se debe dejar en claro que la enfermedad es algo que no se puede eliminar por completo, ya que la misma, indirectamente posibilita la Gran Salud. Es decir, en la enfermedad es donde más se aprende sobre la salud, se podría decir que nos permite superarnos y elevarnos a un estadio superior. ${ }^{3}$

Así como la vida es una expresión de la Voluntad de Poder, el arte -incluyendo también al conocimiento ${ }^{4}$ - también debe ser entendido desde esta noción. De manera opuesta a la actividad científica, que posee métodos de selección y sistematización regulados mediante leyes rígidas que guían su quehacer, intentando así denotar un orden establecido, un orden que no existe, o que existe solo si se toma al azar como moderador, -lo que se parecería al caos más que al orden-. En este punto, Nietzsche nos propone una nueva forma de concebir la ciencia, que se podría decir, es la expresión plena de su dimensión artística, tal como lo veremos más adelante. Esta nueva forma, conlleva entender al arte despojándolo de todos aquellos valores morales, y conciliándolo así, al conocimiento, en otros términos, propone realizar una transmutación de valores sobre el arte y la ciencia.

De la mano con esto, plantea una forma de concebir la belleza en lo artístico y en el arte, sin que este modo que propone esté envuelto en los valores morales que comúnmente se le asigna a la belleza y a la fealdad, así escribe;

3 'Los intentos por anular la voluntad de poder resultan contraproducentes para el cuerpo y para el espíritu. En otras palabras, atenta contra la vida misma del hombre. Niega sus condiciones de posibilidad y lo conduce a encerrarse, disminuirse, resentirse y querer vengarse. Le alimenta la esperanza. Fomenta la espera de algo que nunca llega. Así, lo adormece. Pasa su tiempo, su vida sin proponer nada. Por el contrario, lo convierte en un ser reactivo y dependiente. En un ciego que tampoco tolera a quienes desean sobreponerse. Hay una anulación de los sentidos en lugar de una agudización de ellos.” Ob. Cit. Pp 32

4 El conocimiento también es una expresión de la voluntad de poder. "Antes de ser posible un conocimiento, cada uno de estos instintos ha tenido que proferir previamente su parecer unilateral acerca de la cosa o de un acontecimiento; luego surgió la lucha entre estas unilateridades, y a partir de ella, alguna vez se alcanzó un punto medio, un apaciguamiento, un dar razón a cada una de las tres partes, una especie de justicia y de contrato: pues cada uno de estos instintos puede afirmarse en la existencia mediante la justicia y el contrato, y mantener sus derechos entre sí." ( NIETZSCHE, FRIEDRICH. La ciencia jovial. Trad. José Jara, Monte Ávila, Venezuela, 1999. pp 191). 
"Se le trazan al arte límites demasiado estrechos cuando se exige que en él solo pueda expresarse el alma ordenada, éticamente equilibrada. Como en las artes figurativas, así también en la música y la poesía hay un arte del alma fea además del arte del alma bella; y quizá es precisamente aquel arte el que mejor ha logrado los efectos del arte más poderosos: quebrar las almas, mover piedras y humanizar bestias." 5

Una vez entendido desde este foco, es posible volcar la actividad artística a la vida y comprender por qué y cómo el arte la estimula y transfigura, así como también debe suceder en la ciencia. El arte, entonces, adquiere esta función estimulante en tanto y en cuanto potencia y eleva la vida, posibilitando la apertura de nuevas perspectivas en torno a ella. El vínculo arte-vida, se torna imprescindible, o mejor: vital. Esta vitalidad que solo el arte puede darle a la vida mas allá del arte en sí mismo, ya que si pensamos en una desaparición repentina de este, quedaría en nosotros la perspectiva que por largo tiempo nos dio posibilidad de ver la vida como una actividad en constante transfiguración. En palabras nietzscheanas;

Ante todo, durante milenios [el arte] ha enseñado a ver con interés y placer la vida en todas sus formas y a llevar nuestro sentimiento tan lejos que finalmente exclamemos: ?sea como sea la vida, es buena? Esta enseñanza del arte a gozar de la existencia y considerar la vida humana como una porción de naturaleza, sin conmoción demasiado vehemente, como objeto de evolución conforme a la ley, esta enseñanza ha echado raíces en nosotros y vuelve ahora a la luz como todopoderosa necesidad del conocimiento. Podría prescindirse del arte, pero con ello no se perdería la facultad aprendida de el: tras una desaparición del arte, nunca dejarían de pedir satisfacción la intensidad y la multiplicidad de los goces de la vida implantadas por él. ${ }^{6}$

Se debe remarcar nuevamente que algunas de sus consideraciones de la juventud sufren un giro más tarde, pero no por esto deben ser descartadas, ya que tienen su peso en el conjunto de la filosofía nietzscheana. Un ejemplo oportuno de estas consideraciones es la afirmación que realiza de que el arte es superior al conocimiento, la cual se desvanece en tanto y en cuanto el propio Nietzsche cae en

\footnotetext{
5 Friedrich, Nietzsche. Humano, demasiado Humano. Primer volumen. Trad. Alfredo Botons
} Muñoz. Madrid, Akal, 2007. Pp121 
cuenta de que él mismo está desarrollando y defendiendo un tipo de conocimiento. Es decir, todo lo que esboza sobre el arte en sus escritos anteriores a La Ciencia Jovial constituye una forma de conocer, por lo que afirmar que el arte es superior al conocimiento cae por sí mismo.

Es así que a partir de esta obra, estas consideraciones se consuman y comienza a afirmar que hay una otra forma de conocimiento. En esta nueva ciencia, se concilia lo que venía afirmando sobre lo artístico, aplicándolo al conocimiento: ciencia jovial, ciencia de la alegría y la danza. A continuación, nos enfocaremos en diferenciar en qué puntos especialmente cambian de sentido sus postulaciones de juventud y de adultez, con el fin de que se vislumbre cuales aspectos siguen estando y le sirven para postular una nueva forma de concebir la ciencia que esté en acuerdo con la vida y lo humano.

\section{El arte ¿actividad metafísica de la vida ?}

Nietzsche se opuso tajantemente a la metafísica, tal como lo vemos reflejado claramente en su obra, por ejemplo, con recurrentes referencias críticas a la filosofía platónica, filosofía en la cual se podría decir que inicia el camino de la metafísica occidental. Una de las críticas que le realiza en a la metafísica es que la misma está marcada por valores morales sobre el cuestionamiento del ser. ${ }^{7}$ Asimismo se opone a todo conocimiento que implique consideraciones metafísicas, a todo pensamiento que la legitime; es por esto que su filosofía es una recurrente lucha contra la cultura occidental.

6

Ob. Cit pp 149.

7 ¿Hay que tomar en serio el desprecio que Nietzsche manifiesta por la metafísica, o tal desprecio es solo un orgulloso prejuicio? Sin duda su escepticismo frente a la filosofía occidental a partir de Parménides y de Platón no surgió de un radicalismo que considera insuficiente la pregunta ontológica de la metafísica, de un radicalismo que quiere superarla porque no planteen con bastante decisión la cuestión del ser. El rechazo por Nietzsche de la metafísica y del concepto de filosofía basado en su tradición se origina en un ángulo de visión completamente distinto. La metafísica es vista de manera no ontológica, sino ?moral?; le parece a Nietzsche un movimiento vital en el que se reflejan ante todo ?estimaciones de valor?, un movimiento en que se imponen ?valores? que atrofian, oprimen y debilitan la vida. La metafísica es tomada como un proceso vital que Nietzsche escudriña en cuanto su valor. La ve con la ?óptica de la vida?". (FINK, EUGEN. La Filosofía de Nietzsche. Trad. Andrés Sánchez Pascual. Madrid, 1976) 
Debido a esto, resulta casi contradictorio o paradójico analizar por qué y desde dónde se ubica el joven Nietzsche cuando define el arte como una actividad metafísica de la $v{ }^{8}{ }^{8}$ en el prólogo de su obra juvenil El nacimiento de la tragedia. Si se comprende a la metafísica como aquella actividad que entiende al ser, al mundo y la vida a través de principios, siendo estos causas primeras que posibilitan y regulan un "orden del cosmos"; se puede ver cómo se la destruye y niega en el pensamiento nietzscheano. En contraste a esta actividad, se encargó de abolir todo tipo de conceptos o ideas donde, según se vislumbra, subyace una consideración metafísica en el sentido antes nombrado. Considera así, que los conceptos son fijos e inmutables, y que a través de ellos es imposible designar la naturaleza tal cual es, es decir, lo inexpresable de la misma.

De manera antagónica los conceptos, mediante designaciones limitadas y estructuradas conducen a la negación de la realidad a través del lenguaje, ya que la naturaleza no entiende de conceptos o ideas. No existe un orden establecido en ella, más bien las cosas se encuentran mezcladas y dispersas en un caos que le es propio. El incontrolable afán humano por necesidad comienza a designar las cosas que le rodean, imponiendo a este caos, un orden que, cabe decir, no se corresponde con lo que se supone que designa. De esta manera el orgullo del humano lo hace considerarse superior, pero este saber que cree tener de las cosas, no es más que una manera de conservarse a sí mismo, de hacer soportable lo insoportable.

En directa relación a lo dicho, Nietszche afirma que;

“...durante largo lapso de tiempo el hombre ha creído en los conceptos y nombres de las cosas como en aeternae veritates (verdades eternas), ha hecho suyo ese orgullo con el que se elevaba por encima del animal: suponía tener efectivamente en el lenguaje el conocimiento del mundo. El artífice del lenguaje no era tan

\footnotetext{
8 Nietzsche, culminaba el prólogo de su obra de juventud "El nacimiento de la Tragedia" escribiendo:"Pero acaso cabalmente a esos mismos les resultará escandaloso el ver que un problema estético es tomado tan en serio, en el caso, desde luego, de que no sean capaces de reconocer en el arte nada más que un accesorio divertido, nada más que un tintineo, del que sin duda se puede prescindir, añadido a la «seriedad de la existencia»: como si nadie supiese qué es lo que significa semejante «seriedad de la existencia» cuando se hace esa contraposición. A esos hombres serios sírvales para enseñarles que yo estoy convencido de que el arte es la tarea suprema y la actividad propiamente metafísica de esta vida, en el sentido del hombre a quien quiero que quede dedicado aquí este escrito, como a mi sublime precursor
} 
modesto que creyera que él le daba a las cosas precisamente mas que designaciones, sino que mas bien se figuraba expresar con las palabras el saber supremo de las cosas..."

Si tenemos en cuenta lo mencionado sobre la metafísica occidental, podemos notar cómo el genio de las antinomias produce una vez más un quiebre cuando considera al arte como la actividad metafísica de la vida; ¿en qué sentido se puede dar en el pensamiento nietszcheano? La única manera de que la vida adquiera valor se da en tanto aumente su potencia a través del arte, creando y transfigurándose. Por esto, cuando se habla de que al arte constituye su actividad metafísica, se vale del término $y^{\prime \prime}[\ldots]$ lo aplica en sentido productivo cuando se trata de definir el carácter creador de la vida, en el sentido de que su fuerza originaria trasciende sus mas altas posibilidades en el arte $^{\prime 10}$ Es decir, la referencia que realiza el filósofo, valiéndose de un concepto que él mismo critica, le sirve a la vez para dibujar lo que pretende expresar. Esto tiene que ver exclusivamente con la vida, ya que entiende que esta es artística, en tanto posee una fuerza creadora, y la interpreta como una obra de arte en constante transfiguración.

Por lo tanto, se debe entender esta aparente contradicción, como una vuelta de turca característicamente nietzscheana. Hay que entender que su filosofía tiene la particularidad de ser un como un "juego de máscaras", -utilizando una de sus expresiones-, que no deja ver un solo rostro, sino que debemos contentarnos en ver multiplicidad de ellos, sin la certeza de saber cuál es el verdadero o mas bien, si realmente existe uno verdadero. Con esto hacemos referencia a las numerosas y disímiles interpretaciones a la que se prestan sus escritos, debido a tantas contradicciones e incoherencias aparentes. También debería considerarse que su filosofía es experimental, y que de esto se tratan también los recurrentes cambios de significación, de mostrar que es un experimento. Pero cabe tener en cuenta y es

en esa vía." (NIETZSCHE, FRIEDRICH. El nacimiento de la tragedia. Trad. Andrés Sánchez Pascual, Alianza, madrid, 2004.pp 40).

9 NIETZSCHE, FRIEDRCH. Humano, demasiado humano. Primer volumen. Trad. Alfredo Botons Muñoz. Madrid, Akal, 2007. "De las primeras y las últimas cosas" (Af. "El lenguaje como presunta ciencia").

GUERVÓS, LUIS E. DE SANTIAGO. El arte como función de la vida en Nietzsche. Universidad de Málaga, España, 2000. pp 248 
necesario tener precaución debido a que sus palabras no son ingenuas, sino que están pensadas con un propósito, sobre todo prestando atención a su profesión de filólogo. Esto se podría pensar como una pretensión de provocar esta ruptura y esta confusión, otorgando así la responsabilidad de interpretación al lector.

Hay quienes al desarrollar nociones de Nietzsche realizan una suerte de vinculación íntima con la vida errante que tuvo éste, no se pretende realizar aquí una reproducción de ello, a pesar de que se comprende las influencias de las circunstancias que llevaron al filósofo a pensar determinadas cosas y no otras. Pero, es necesario aclarar que Nietzsche, influenciado por circunstancias de su vida, produjo un giro en la manera que concibió al arte en su juventud, definiéndolo como metafísico, y al arte de su periodo de madurez, caracterizado por un tinte experimental.

Si bien hay vestigios que siguen estando, en su madurez ya no es el arte una actividad metafísica de la vida, sino más bien aquel que permite afirmarla, que permite hacer un experimento de ella. Adquiere un notable aspecto fisiológico. Un arte de vincularse íntimamente con la vida. Alejándose de la seriedad propia de la ciencia y fomentando el juego, el baile y la risa, en fin, afirmándola y potenciándola. Donde la figura del artista también está acorde a esta forma de concebir el arte. "La tarea del artista adquiere una responsabilidad mayor. El artista se encuentra ahora en sintonía con la tierra y con la vida misma. Su obrar, en tanto asume una voluntad de poder afirmativa, puede encausarse en algo grandioso. Es decir, en el sí a la vida." ${ }^{11}$ Un arte que pretende plasmar en la ciencia: ¡Ciencia Jovial!.

Como es visible, continúa entendiendo al arte en estrecha relación con la vida, pero sin definirlo como una actividad metafísica, sino mas bien, como una forma en la que debe expresarse la vida, una nueva forma de entenderlo fisiológica u orgánicamente, en contacto con lo bajo, con el experimento. “iNo, si nosotros los convalecientes requerimos todavía de un arte, ése es otro arte -un arte burlón, ligero, fugaz, divinamente despreocupado, divinamente artístico, que ardo como una llama resplandeciente en un cielo sin nubes!"12 Este notable cambio de sentido en el 
pensamiento nietzscheano, no debería entenderse como una contradicción, sino más bien como una nueva forma de interpretar al arte. Este nuevo sentido que está más acorde a lo experimental, y cada vez más lejos de la objetividad.

\section{La vida experimental y el rol del filósofo-artista}

En sus jóvenes escritos, Nietzsche realiza varias referencias a la apariencia como el modo más soportable de vernos a nosotros mismos. La profundidad, entendida de esta manera, está en la apariencia. Se refiere en reiteradas ocasiones a los griegos, quienes dejaron el legado del arte de ponerse en escena a uno mismo, ya que posibilitó que el hombre pueda verse ante una distancia, en la cual realiza un aumento de sus virtudes y una supresión de los defectos, a fin de que se aprecie y soporte lo que se es, los griegos fueron los únicos que entendieron esta cuestión de lo aparente.

En un principio parecería dividir el mundo en real y aparente. Pero luego puede verse como el filósofo de alguna manera rompe con la dicotomía "mundo real" y "mundo aparente". Se pregunta ¿qué es para mí ahora la apariencia?. Con esta pregunta, produce una notable ruptura en contraste al valor que le daba anteriormente a la apariencia sobre la verdad, ya que desde ahora se comienza a mostrar más clara y fuertemente que lo que existe es solo caos. No existe la cosa en sí, que no existe la verdad esencial. La apariencia es lo que enmascara al caos mismo, desordenado, mezclado y en continuo movimiento. La apariencia es lo que cada uno interpreta del mundo para que éste le sea soportable. Desde esta posición es que se responde.

“La apariencia es para mí lo que actúa y lo viviente mismo, yendo tan lejos en su burla de sí misma como para hacerme sentir que aquí no hay más que apariencia, luces fatuas y baile de espíritus que entre todos estos soñadores también yo, el <que conoce $>$ bailo mi baile $[\ldots]^{\prime 13}$

$13 \quad$ Ob. cit. Pp 64 
A partir de aquí, se puede notar también que comienza a autodenominarse "el conocedor", con lo que podría querer mostrar que defiende una forma de conocer y, a la vez, que hace frente a la ciencia que se determina por valores morales. Con respecto a esto, se inserta la cuestión sobre la voluntad de verdad, esta voluntad de volver pensable todo lo que nos rodea. Una voluntad que prefiere la certeza en lugar del error y que por esto mismo está guiada por ciertos valores, los cuales tienen como fin volver soportable lo insoportable.

Esto se puede plasmar incluso en los artistas, como lo dice el propio Nietzsche, al "[...]alejarse de las cosas hasta que ya no se vea mucho de lo que le es propio y tener que agregarles mucho al mirarlas, para continuar viendo [...] o darles una superficie y una piel que carezca de una transparencia total: todo eso debemos aprender de los artistas" ${ }^{14}$. Toda esta transfiguración también es una forma de interpretar el mundo, de volverlo soportable. Pero, luego añade una notable consideración que tiene que ver con una divergencia entre el artista y el filósofoartista. Este último no debe abandonar esa fuerza artística, de manera que continúe poetizando hasta su propia vida. Al parecer con esto está aludiendo a que el arte de ponerse en escena debe ser un arte que se reproduzca en lo más cotidiano de la vida, en el sentido de embellecerla, de afirmarla.

Es necesario desarrollar esto sobre la apariencia, debido a su relación con la vida experimental que propone Nietzsche. En este punto, la cuestión del orden, como algo que pretende ocultar el caos, este caos que no se entiende y que, por esto, produce una incomodidad, es una respuesta netamente humana. A partir de la cual el desorden es visto cargado de error, como aquello que se debe evitar. El mundo aparente aquí constituye una manera de suplir este desorden, una manera de interpretarlo. En este sentido, Nehamas, expone en su obra "La vida como literatura" sobre cómo, a su modo de ver, Nietzsche ve al mundo de modo monista:

“[...]el mundo no es lo que indican nuestras mas acertadas, esenciales y poderosas convicciones; para él es otra cosa. En consecuencia, cabe atribuirle la noción de que, en sí mismo, el mundo se caracteriza por rasgos que ni toda nuestra ciencias ni

$14 \quad$ Ob. Cit. pp 174. 


\section{REVISTA DE INVESTIGACIONES EN FILOSOFIA}

todas nuestras disciplinas, ni siquiera en su estado más avanzado puedan aprehender. Pero en su perspectivismo [...] parece subyacer precisamente el intento de desenmascararse de la idea de que el mundo posee algún tipo de rasgo previo a, o independiente de, la interpretación" ${ }^{15}$

Se considera oportuno quedarnos con la imposibilidad de que el mundo posee algo a priori, que no sea nada más que una interpretación, que sirve para poder ordenarlo si se quiere, y engañarnos de que lo conocemos y entendemos. Y esta distinción que se realiza aquí, es fructífera para entender el mundo como caos. No se trata de que no se pueda aprehender de él, sino más bien de que no hay nada que en nuestra capacidad de humanos nos conduzcan a aprehender del mundo. A partir de esto, cobra importancia su perspectivismo y su postulación de que solo existen interpretaciones.

A toda esta costumbre de "ordenar" el mundo, Nietzsche opone la ciencia jovial. En la cual, a través de una trasvaloración, permite ver al desorden y al caos como parte inherente y necesaria de la vida misma y afirmarlo como tal. En este marco, no es la razón algo necesario, su lugar lo ocupa ahora la risa, que festeja y danza en este caos. También la razón es suplantada por el juego, que permite burlar a la seriedad que representa esta racionalidad. Así es que, también, la locura aquí es vista como la condición que posibilitó la permanencia que tuvo toda la humanidad, sin la cuál hubiese perecido. Asimismo, el rol del loco, a quién comúnmente se lo excluye por denominarlo "anormal" o "peligroso", es tomado aquí como una figura que representa todo esto que viene proponiendo Nietzsche sobre la ciencia y el conocimiento."No es la verdad ni la certeza lo opuesto al mundo del loco, sino la universalidad y compromiso total de una creencia, en pocas palabras, lo no discrecional en el juicio." ${ }^{16}$

Como se vislumbra, Nietzsche se opone a los procedimientos científicos y a su imposición de la verdad como una necesidad de conocerla. Rechaza la sistematización y estructuración de la ciencia, las leyes mediante las cuales opera la misma, los

\footnotetext{
15 NEHAMAS, ALEXANDER. Nietzsche: La vida como literatura. Trad. Ramón J. García. Fondo de Cultura Económica, México, 2002. Pp 66

16 NIETZSCHE, FRIEDRICH. La ciencia jovial. Trad. José Jara, Monte Ávila, Venezuela, 1999. Pp 76
} 
conceptos lógicos que utiliza, aspectos que, según indica, nada tienen que ver con la naturaleza, sino que por el contrario, niegan la vida al conservarla. En contraste, propone darle valor a la vida experimental, una vida tal que es digna de ser vivida y afirmada, un experimento que se guíe a si mismo, sin depender de los ideales metafísicos y morales. Respecto de esto, escribe: “iLa vida no me ha defraudado! Antes bien, de año en año la encuentro más verdadera, más deseable, más misteriosa desde aquel día en que vino a mi el gran liberador, aquel pensamiento de que la vida ha de ser un experimento de los que conocen- iy no una obligación, no una fatalidad, no un engaño!-"17

Se debe señalar que lo que pretende mostrar el autor en la obra La Ciencia Jovial, es un espíritu alegre el cual juegue con la seriedad establecida por siglos respecto de la ciencia, una seriedad que niega al hombre y a la vida. Y en este punto, el rol del artista va en contra de toda esta racionalidad, de todo este cultivo de la cabeza que por siglos se fue desarrollando, comenzando desde Sócrates. Ante toda esta seriedad científica, Nietzsche propone hacer de la ciencia y la vida un experimento. A partir de ahora el filósofo-artista es quién debe aniquilar y crear nuevos conceptos, transvalorados, es decir, nociones que estén más allá de lo que se considera mentira y verdad, o más bien, de lo que moralmente se dice entorno a esos conceptos.

Al salirse de esto, se ubica al filósofo-artista en un plano donde crea, afirmando la vida. Lo que no es nada fácil, ya que este plano desde donde se crea debe tener asumido que debajo de las ilusorias representaciones morales, no existe mas que el caos. Un caos que está siempre desafiando. Y también debe tener en cuenta que luego de la muerte de Dios tiene que tomar una postura de manera creativa, teniendo presente la no-existencia de bases sólidas o de fundamentos ${ }^{18}$. Debe poder conllevar esto, y sin renegar, danzar libremente. $Y$ todo esto es posible en tanto y en cuanto el

\footnotetext{
$17 \quad$ Ob. Cit pp 186

18 "Matar a Dios y no crear nada nuevo es más peligroso que ser un mero nihilista pasivo. Dejar un vacío tras la muerte de Dios implicaría el riesgo de que los hombres sean tentados a tapar el abismo con un valor o una figura mucho más rígida que la eliminada. El espíritu libre es el primero que asume el riesgo de crear un ámbito distinto. Busca borrar a Dios y el vacío que queda en el lugar de este. Es necesario evitar considerar a la transvaloración como una simple inversión de los valores. Transvaloración implica una transformación total y mucho más profunda."( ALDONATI, LUCAS GONZALO Artista
} 
filosofo-artista se valga de la voluntad de poder y sepa como sobreponerse a esta. Así, al encausar su propia voluntad, podrá actuar en concordancia con la vida, es decir, afirmándola y potenciándola."El filósofo-artista es quien hace del mundo un recreo. El mundo deviene entre sus manos un espacio de juego. Todo y nada se crea y se re-crea a partir de la voluntad que esparce el artista". ${ }^{19}$

Esta postura implica comprender que la trasvaloración de la que habla Nietzsche, no está sujeta a un cambio de estos valores que considera nocivos para la vida, por otros a los que considera que afirman la vida. No existe tal dicotomía para él, en cambio lo que pretende plantear es una nueva forma de vincularse con los valores, teniendo en cuenta que no existe un suelo firme donde posicionarse, no existe una verdad absoluta, no existe un Dios, no existen leyes. A partir de comprender esto, posicionarse en la inseguridad misma y experimentar, de esto se trata el experimento. crear y aniquilar, jugar con los conceptos, hacer una ciencia alegre y jovial, nuevamente.

\section{Arte y ciencia, ¿polos opuestos?}

Prestando especial atención a lo desarrollado sobre el arte y la ciencia desde Nietzsche, se torna compleja la cuestión de definir una relación entre ambas dimensiones. La actividad científica tan criticada por el filósofo, con procedimientos "objetivos", la necesidad de una verdad envuelta en términos absolutistas, con parámetros de sistematicidad y universalidad, suprime todo aquel ingenio artístico que condujo a un individuo, desde su singularidad y particularidad, a crear una hipótesis. Una primera hipótesis o idea que a través de estos procedimientos de cientificidad a los que se somenten las teorías, se le imponen tintes objetivos y queda totalmente deformada respecto de lo que comenzó siendo. Pero al fin y al cabo, lo que le dio origen son las propias ocurrencias de este individuo.

como espíritu libre en La ciencia Jovial y Así habló Zaratustra de Friedrich nietzsche. Tesis de Licenciatura. 2017 pp 67)

19 ALDONATI, LUCAS GONZALO Artista como espíritu libre en La ciencia Jovial y Así habló Zaratustra de Friedrich nietzsche. Tesis de Licenciatura. 2017 pp 127. 
Se comprende que Nietzsche postula sus consideraciones desde un perspectivismo, que nada tiene que ver con lo subjetivo, sino que está determinado de manera inmanente por la noción de Voluntad de Poder. Entonces, genealógicamente hablando, si se tiene en cuenta al científico como persona que investiga, despojándolo por un momento de todos sus obligaciones científicas, podríamos decir adecuándonos al pensamiento nietzscheano, que existe un devenir sin predeterminación en este, manipulado desde la Voluntad de Poder a través de azar que esta implica, que lo condujo a elaborar una hipótesis o teoría (y no otra), dada a través de un instinto afirmador de esta lucha de fuerzas que implica la Voluntad de Poder.

¿Podríamos decir que la ciencia es artística en sus bases? ¿Cómo sostener tal afirmación? De acuerdo a lo expuesto, podríamos hablar de una dimensión artística y creadora en la base la ciencia, es decir, en el origen de ella. La cual luego queda invisibilizada por el cúmulo de procedimientos objetivos y de universalización bajo el cual se la somete. En este sentido, se podría relacionar lo expuesto con esto que escribe Nietzsche sobre la necesidad de la verdad por parte de la ciencia, donde las ocurrencias del científico no deben trascender ni interesar. "Las naturalezas científicas saben en cambio que el don de tener ocurrencias de todas las clases debe ser refrenado del modo mas riguroso por el espíritu de la ciencia; no lo brillante, aparente, excitante, sino la verdad con frecuencia inaparente es el fruto que este desea arrancar del árbol de la ciencia" 20

Se ve claramente que este don, como lo denomina, no solo pretende la verdad absoluta, sino que debajo de esa pretensión de objetividad y universalidad subyace una negación a la vida y a las posibilidades humanas que son inaceptables. De esta manera, todo aquello que el humano crea, es destruido en estos términos, es separado para ser analizado, es medido a través de leyes, es calificado a través de verdades y falsedades.

Para finalizar, se pretende resaltar nuevamente la ciencia experimental que nos propone, y poder ver que mas allá de todos los procedimientos científicos se encarguen de ocultar este origen artístico de la ciencia, en tanto creador, la misma 
experiencia científica nos muestra el engaño que envuelve su verdad absoluta, y se dice esto pensando en todas aquellas teorías reemplazadas, que fueron probadas "objetivamente" y aún así refutadas, que se abandonaron y se consideraron falsas luego de años de vigencia. De esta manera, muy optimista quizás, podemos ver que, a pesar de la voluntad de verdad que se impone en la ciencia, con todo lo que ello implica, no se puede hacer frente al caos existente, no es posible una verdad en estas condiciones. La verdad absoluta, la verdad divina no tiene vigencia, no puede tenerla debido a lo mencionado. En el mismo camino de la ciencia se demuestra que lo que hoy se considera absoluto, puede ser refutado en cualquier momento.

Es la pregunta que Nietzsche se realiza en la Ciencia Jovial, “¿Pero qué pasaría si esto se vuelve cada vez más increíble, si ya nada más se mostrase como divino, a menos que lo sea el error, la ceguera, la mentira -si Dios mismo se mostrase como nuestra más larga mentira?"21. La respuesta fue escabulléndose a lo largo de toda la obra, y la misma tiene que ver con su propuesta de hacer un experimento de la ciencia y la vida, teniendo en cuenta la transvaloración de las mismas, como lo dijimos anteriormente. Un experimento sobre el plano mismo de la inseguridad, o de la seguridad de saber que no hay nada como una verdad o como principios que regulen el mundo. Posicionarse en ese plano y desde allí crear, asumiéndose como filósofoartista. En este crear se afirma la vida, estando así en constante transfiguración. De esto se trata el modo de hacer ciencia que nos propone, y el cual representa un gran desafío sumirse.

\section{Conclusión}

Para concluir, es necesario indicar que ningún punto desarrollado aquí podría ser realmente concluido en un trabajo de este calibre. Pero cabe admitir que sirve muy bien, para poner sobre la mesa ciertas nociones básicas sobre cómo concibe el arte y la

20 Friedrich, Nietzsche. Humano, demasiado Humano. Primer volumen. Trad. Alfredo Botons Muñoz. Madrid, Akal, 2007. Pp 171

21 NIETZSCHE, FRIEDRICH. La ciencia jovial. Trad. José Jara, Monte Ávila, Venezuela, 1999. pp 206 
ciencia en la filosofía nietzscheana. Si nos valemos del perspectivismo que éste pretende y defiende, podemos decir que la perspectiva o interpretación que planteamos aquí, puede muy bien no seguir a lo que comúnmente se piensa sobre el filosofo, pero podría valer como interpretación. Esto también va de la mano con lo que en alguna parte se hizo mención, esta filosofía es un experimento, pretende mostrar que todo debe serlo. Así es que se podría sacar un hilo de cada temática abordada y re-significarla, verla desde otra perspectiva.

Recapitulando, se intentó mostrar que el arte y la vida son inseparables en esta filosofía. A pesar del cambio de sentido que se produce en Nietzsche, nunca separa al arte de la vida, lo que nos dice mucho de la importancia artística. Quizás es muy complejo definir a la vida en su pensamiento, pero en vinculación con el arte podemos hacernos una mejor visión sobre ella. Teniendo en cuenta las diferentes significaciones: en un primer momento el arte era considerado metafísico, permitía la transfiguración y potenciación de la vida. Luego, el arte adquiría un sentido en conexión con la tierra, es decir, fisiológico, experimental; y permitía que la vida sea un experimento. Esto último se podría lograr en tanto y en cuanto, se entienda al mundo como algo caótico, sin considerar la existencia principios basales que expliquen o determinen el devenir. Aquí se imponía el desafío de la figura del filosofo-artista asumiendo este lugar, entendiendo la no-existencia de causas primeras, en ningún sentido: sin religión, sin ciencia, sin conceptos. Pero asumiéndolo de una manera creativa, sin pesimismos, sino mas bien experimentando: creando y aniquilando conceptos, de manera continúa. Todo esto quedaría expuesto en una nueva forma de conocer y relacionarnos con el mundo, una ciencia que este del lado de la vida, que la afirme como tal, una ciencia alegre y que diga sí.

La pretensión de ver en la actividad científica también un arte concebido de la forma nietzscheana, podría causar ciertos rechazos. Pero viéndolo de un manera mas bien subjetiva, lo que se intenta es mostrar que incluso la misma ciencia pretendiendo objetividad, parte de un terreno muy diferente, muy subjetivo. Un terreno creativo y artístico en muchos casos. Y a partir de esto, quizás muy precipitadamente, se intentó 
relacionar la cuestión artística en tanto creadora, y creadora muchas veces, para poder soportar lo insoportable con la ciencia racional que termina siendo.

Los objetivos con los que se encaró el trabajo fueron alcanzados en cierta medida. Un pensador de esta índole es difícil de abordar en su totalidad, ya que siempre surgen nuevas visiones, nuevas consideraciones que hacen replantear una y otra vez lo interpretado en cada lectura. Y quizás esto es lo que este filósofo pretendía causar en sus lectores. El lector cree fervientemente que lo entiende, pero Nietszche se burla de esto cuando aquel emocionado emprende el siguiente aforismo.

La presente investigación podría continuarse de diversas maneras. Podríamos abocarnos sobre todo la temática de la transvaloración de los valores morales, que se hace mención pero no se profundiza aquí. Se podría hacer especial énfasis en cómo estos valores morales contaminan al hombre, lo hacen vivir un engaño no solo respecto del conocimiento, sino de todos los aspecto de la vida. Y pensar esto, no tanto en contra el cristianismo, como el pensó. Sino para criticar por ejemplo, los medios de comunicación que educan e imponen ciertos valores morales sobre las masas. Estos valores, van configurándose hasta considerarse una verdad. Una verdad que se arraiga en estructuras mentales y se reproducen acríticamente formando un conglomerado con el que muchas veces se torna complejo luchar.

\section{BIBLIOGRAFÍA.}

Fuentes directas:

- NIETZSCHE, FRIEDRICH. El nacimiento de la tragedia. Trad. Andrés Sánchez Pascual, Alianza, madrid, 2004.

- NIETZSCHE, FRIEDRCH. Humano, demasiado humano. Primer volumen. Trad. Alfredo Botons Muñoz. Madrid, Akal, 2007.

- NIETZSCHE, FRIEDRICH. La ciencia jovial. Trad. José Jara, Monte Ávila, Venezuela, 1999. 
Bibliografía sobre el tema:

- $\quad$ ALDONATI, LUCAS GONZALO Artista como espíritu libre en La ciencia Jovial y

Así habló Zaratustra de Friedrich nietzsche. Tesis de Licenciatura. 2017.

- $\quad$ GUERVÓS, LUIS E. DE SANTIAGO. El arte como función de la vida en Nietzsche. Universidad de Málaga, España, 2000.

- HEIDEGGER, MARTIN. Nietzsche (Tomo I). Trad. Juan Luis Vermal, Barcelona, Ediciones Destino, 2002, 2 tomos

- $\quad$ PIfARRÉ, LLUIS. Nietzsche como artista. PPU. 1996.

- VERMAL, JUAN LUIS. Poesía y verdad en Nietzsche. Universidad de Barcelona, 2005

Bibliografía de consulta:

- FINK, EUGEN. La Filsofía de Nietzsche. Trad Andrés Sánchez Pascual. Madrid, 1976

- NEHAMAS, ALEXANDER. Nietzsche: La vida como literatura. Trad. Ramón J. García. Fondo de Cultura Económica, México, 2002.

- NeIMAYER, CHISRTIAN. Diccionario Nietzsche. Ed. Biblioteca Nueva. Madrid, 2012.-

- NIETZSCHE, FRIEDRICH. Ecce homo: Cómo se llega a ser lo que es. Ed Alianza, España, 2005.

- $\quad$ SLOTERDIJK, PETER. El pensador en escena. El materialismo de Nietzsche. Trad. Germán Cano. Ed. Pre-textos, Valencia, 2000. 